\title{
As contribuições e os limites do Pibid como política governamental para a formação docente
}

Paulo César Geglio* Anna Karolina Fidelis da Silva**

\begin{abstract}
* Professor do curso de Ciências Biológicas da Universidade Federal da Paraíba (UFPB) pgeglio@yahoo.com.br
\end{abstract}

**Acadêmica do Curso de Licenciatura em Ciências Biológicas da UFPB e bolsista do Programa Institucional de Bolsa de Iniciação à Docência (Pibid) anna_karolinafs@hotmail.com
Resumo: O Programa Institucional de Bolsa de Iniciação à Docência (Pibid) já está consolidado como política governamental para a formação docente. A Coordenação de Aperfeiçoamento de Pessoal de Nível Superior (Capes), órgão ligado ao Ministério da Educação (MEC) e os participantes do programa nas instituições de ensino superior (IES) o consideram importante para a formação inicial e continuada do professor, bem como para a melhoria da qualidade do ensino nas escolas públicas de educação básica e para a valorização do magistério. Concordamos com a importância dele para a formação inicial e apresentamos, no presente texto, nossa experiência nesse sentido. Porém, mais que isso, suscitamos uma discussão a respeito das limitações do programa, no que se refere à abrangência de beneficiados, e quanto aos demais aspectos apontados pelos bolsistas e pela Capes. Concluímos sobre a necessidade de ampliação do programa e maior compromisso das IES com ele e com a formação docente.

Palavras-chave: Políticas públicas governamentais. Pibid. Formação docente. 
INTRODUÇÃO

Podemos considerar que nos últimos dez anos, pelo menos, a preocupação com a formação de professores na América Latina tem figurado como tema central das políticas públicas governamentais de educação (VEZUB, 2005, 2007). Nesse contexto, podemos supor que todas as discussões sobre educação, certamente, incluem aspectos relativos à formação inicial e continuada, condições de trabalho, identidade profissional e características da prática docente (POGGI, 2006). A maioria das reformas no campo da educação, por sua vez, empreendidas nos países dessa parte da América incluiu, segundo Vezub $(2005,2007)$, ações voltadas para a formação e o fortalecimento profissional dos professores. Não obstante, a autora ressalta que, apesar dos esforços, os resultados efetivos na melhoria da qualidade da aprendizagem dos alunos não foram os esperados, sobretudo se considerarmos os investimentos financeiros.

No Brasil, faz-se necessário entendermos as políticas públicas governamentais para a formação, o incentivo e a valorização da profissão docente considerando, antes de tudo, a extensão territorial do país, as diferenças regionais, a autonomia e a condição econômica dos entes federados (estados e municípios), pois essas particularidades podem configurar entraves e facilidades para a implantação de ações voltadas para a educação e para a formação dos professores.

Davis, Nunes e Almeida (2011) e Gatti, Barreto e André (2011) ressaltam, em suas pesquisas, a implementação de ações pelos poderes governamentais, nas diferentes regiões brasileiras, que visam a promoção da formação dos professores, a valorização e o incentivo à permanência na carreira. Porém, nesses estudos, as autoras também revelam que, em função dos fatores mencionados a respeito das particularidades do país, nem todos os professores em território nacional recebem formação ou incentivos suficientes para desenvolver bem a sua função. Nesse caso, elas se referem ao professor que já está efetivamente no desenvolvimento de suas funções, ou que está iniciando-as em uma escola da rede municipal ou estadual. Em relação ao professor iniciante, a pesquisa realizada por André (2012) mostra que há iniciativas dos poderes públicos locais e estaduais em inserir e incentivar a permanência do professor na escola e na profissão, porém são escassas, não abrangem todas as localidades do Brasil. 
No que diz respeito às ações do governo federal para a formação docente destacamos, nesta discussão, o Programa Institucional de Bolsa de Iniciação à Docência (Pibid) - instituído a partir da Portaria Normativa no 38/2007, pelo Ministério da Educação (MEC), com a operacionalização da Coordenação de Aperfeiçoamento de Pessoal de Nível Superior (Capes) e recursos do Fundo Nacional de Desenvolvimento da Educação (FNDE) -, cujo propósito é fomentar a iniciação à docência em nível superior, em cursos de licenciatura presenciais e melhoria da educação básica pública. No ano de 2010, o Pibid se tornou política pública institucionalizada por meio do Decreto Presidencial no 7.219. De acordo com a Portaria no 96/2013 da Capes, são objetivos do programa:

I) incentivar a formação de docentes em nível superior para a educação básica;

II) contribuir para a valorização do magistério;

III) elevar a qualidade da formação inicial de professores nos cursos de licenciatura, promovendo a integração entre a educação superior e a educação básica;

IV) inserir os licenciandos no cotidiano de escolas da rede pública de educação, proporcionando-lhes oportunidades de criação e participação em experiências metodológicas, tecnológicas e práticas docentes de caráter inovador e interdisciplinar que busquem a superação de problemas identificados no processo de ensino-aprendizagem;

V) incentivar escolas públicas de educação básica, mobilizando seus professores como coformadores dos futuros docentes e tornando-as protagonistas nos processos de formação inicial para o magistério; $e$,

VI) contribuir para a articulação entre teoria e prática necessárias à formação dos docentes, elevando a qualidade das ações acadêmicas nos cursos de licenciatura (BRASIL, 2013, p. 2).

Em nossa compreensão, a visão do órgão público (MEC/Capes) é de que a melhoria da qualidade da educação básica oferecida nas escolas públicas se efetiva na medida em que, em primeiro lugar, os licenciandos auxiliam os professores em suas atividades e, em segundo lugar, pelo próprio professor da escola pública se envolver com as atividades programadas em parceria com as universidades. Esse processo gera uma confluência de ações que realça a formação do futuro professor, ao participar e refletir sobre a realidade objetiva com a qual atuará, ao mesmo tempo que provoca o professor da escola pública a dinamizar suas aulas e também o responsabiliza pela formação do primeiro. Assim, o programa se vê atuando em três vertentes: a formação inicial, a formação continuada e as práticas de ensino e de aprendizagem. Essa perspectiva é expressa pela Capes, registrada no relatório de um estudo que ela encomendou à Fundação Carlos Chagas sobre o Pibid: 
O Pibid, contudo, não é simplesmente um programa de bolsas. É uma proposta de incentivo e valorização do magistério e de aprimoramento do processo de formação de docentes para a educação básica. Os alunos de licenciatura exercem atividades pedagógicas em escolas públicas de educação básica, contribuindo para a integração entre teoria e prática, para a aproximação entre universidades e escolas e para a melhoria de qualidade da educação brasileira [...]

(GUIMARÃES, 2014, p. 5).

Em tese, concordamos com o entendimento expresso pelo dirigente da Capes. Vários trabalhos de pesquisa e ensaios vêm sendo realizados com a intenção de mostrar a contribuição do Pibid para a formação inicial de professores, o que pode ser comprovado pelos anais de encontros e reuniões de entidades como a Associação Nacional de Pós-graduação e Pesquisa em Educação (Anped), Associação Nacional de Política e Administração da Educação (Anpae) e Encontro Nacional de Didática e Prática de Ensino (Endipe), assim como nos registros do Encontro Nacional das Licenciaturas e Encontro Nacional do Pibid e no banco de teses da Capes, que no ano de 2012 registra a existência de pelo menos dez dissertações de mestrado sobre o tema. Essa importância do Pibid no cenário educacional atual também é registrada em trabalho realizado por Gatti et al. (2014, p. 15) e mostra a relevância do programa no contexto dos cursos de formação de professores, assim como sua presença no ambiente escolar.

O trabalho de Gatti et al. (2014) consiste em uma análise amostral de dados coletados pelaCapes, pormeio dequestionário eletrônico, juntoaos bolsistas do programa (coordenadores institucionais, coordenadores de área, professores supervisores que atuam nas escolas e alunos dos cursos de licenciatura) de instituições que participam do Pibid. A conclusão, segundo os autores, é de que os participantes do Pibid o consideram muito bom como política pública governamental para a formação inicial e continuada de professores, assim como para a melhoria da educação básica. Os respondentes do questionário aplicado pela Capes quase não apresentam pontos negativos e as críticas ou ressalvas que fazem são relativas à ampliação do programa, aumento no valor da bolsa financeira concedida aos licenciandos, desburocratização de processos financeiros, maior divulgação dos trâmites processuais do programa e simplificação dos relatórios de atividades exigidos pelo órgão.

Não obstante o relevante papel que educadores têm dado ao Pibid para a melhoria da qualidade da educação básica na realidade nacional, consideramos de igual importância suscitar aspectos do programa que, em nossa visão, necessitam ser observados e discutidos, visando ao seu aperfeiçoamento. Assim, nosso objetivo neste trabalho é, por um lado, apresentar ações 
realizadas no contexto do Pibid que caracterizam a efetiva contribuição do programa para a formação inicial e também continuada de professores, bem como para a melhoria da qualidade do ensino oferecido nas escolas públicas de educação básica e, por outro, as limitações do programa nessa empresa. É com essa perspectiva que sugerimos como foco temático deste texto as possibilidades e os limites do Pibid como política pública governamental para a formação docente. Para esta discussão, focalizamos nossas experiências no contexto do curso de licenciatura em Ciências Biológicas do Centro de Ciências Agrárias (CCA), da Universidade Federal da Paraíba (UFPB), a partir do qual são desenvolvidas atividades em duas escolas públicas localizados no interior do Nordeste do Brasil.

\section{O PIBID NA FORMAÇÃO DO PROFESSOR:}

O EXEMPLO DO CURSO DE BIOLOGIA DO CCA/UFPBS

Um dos aspectos importantes na problemática que envolve a formação inicial dos professores diz respeito à prática, à vivência no cotidiano escolar, ao lócus da futura atuação profissional. Esse requisito da formação é tão necessário durante o processo quanto os próprios saberes que consubstanciam e conformam o campo teórico da profissão. Vários autores têm se ocupado desse importante momento da formação (BALL; COHEN, 1999; BALL; FORZANI, 2009; ZEICHNER, 2010), cuja base da discussão é a relação entre a teoria e a prática. Para os autores citados, é fundamental que a formação inicial do professor contemple a atuação com a realidade do trabalho de ensino, pois a teoria, por si, não é suficiente para explicar a imprevisibilidade do ato de ensinar.

No modelo tradicional de formação profissional, como lembra Zeichner (2010), a perspectiva é de que os formandos devem aprender primeiro os saberes da teoria, para depois aplicar tal conhecimento na prática, o que ocorre, geralmente, por meio dos estágios curriculares de docência. Porém, sabemos que essa prática, realizada de maneira pontual como forma de aplicação da teoria, não é suficiente e legítima para subsidiar uma formação que envolve relações complexas e contextuais como a educação. Embora seja preciso reconhecer que o trabalho do professor requer a aplicação de técnicas específicas, de saberes próprios da pedagogia, a forma de aplicá-los varia em relação ao ambiente e às pessoas com as quais o professor atua. Portanto, não se trata do uso comum de certos procedimentos em qualquer situação, 
uma vez que os sujeitos e as condições que compõem o processo educativo são variáveis, são contextuais, são imprevisíveis. Isso significa que aprender a utilizar certas técnicas para uma realidade não é garantia de sucesso em momentos e espaços distintos. Em educação, não há saberes pedagógicos e técnicas universais que possibilitam o sucesso de aprendizagens em situações e contextos transitórios.

Não se trata, no entanto, de fugir de uma racionalidade primária - baseada na visão de que a inteligência opera por meio da aquisição de saberes e técnicas, que posteriormente são aplicados na resolução de problemas universais - e aderir a um pragmatismo aleatório - que parte do princípio de que todo conhecimento só é válido se for útil e imediato. Não é essa tese que defendemos. Os saberes da teoria que constituem o campo epistêmico da educação e de suas subáreas, como, por exemplo, a didática, são importantes e fundamentais na formação inicial do professor, mas não podem ser concebidos como norteadores da prática. É preciso considerar que existe uma relação dialética, expressa em uma ação de confronto e síntese, entre a teoria e a prática, que, conforme Vasquez (1977, p. 54), assenta-se no conceito de práxis em Marx, pois “[...] uma verdade objetiva não é teórica, mas prática. É na práxis que o homem deve demonstrar a verdade [...]”. A práxis se configura, portanto, como síntese da relação de confronto entre a teoria e a prática. Não é totalmente nem uma e nem outra, mas contém elementos das duas. É o próprio Marx que afirma, no Capital, que a distinção entre o homem e o aninal é a capacidade do primeiro em projetar na mente aquilo que transformará em realidade. Assim, compreendemos que para Marx a práxis é a síntese da relação entre a teoria e a prática, aquilo que idealizamos, projetamos, teorizamos e aquilo que realmente conseguimos realizar. 0 ideal é puro, não contém imperfeições, vicissitudes; o real, por sua vez, é mutável, resistente às idealizações, não se deixa dominar em única ação.

É com essa perspectiva de formação, baseada na relação entre a teoria e a prática, que evidenciarmos ações propiciadas pelo Pibid na formação inicial de professores. Para isso, tomamos como exemplo o curso de licenciatura em Ciências Biológicas do Centro de Ciências Agrárias (CCA) da Universidade Federal da Paraíba (UFPB) (campus II), cuja participação no Pibid ocorre desde 0 ano de 2010. No decorrer de quatro anos, mais de 80 licenciandos do referido curso já passaram pela experiência de atuar diretamente nas escolas parceiras do programa junto ao curso. O campus II da UFPB está situado em uma cidade localizada no Brejo Paraibano. As atividades do Pibid de biologia 
são desenvolvidas em duas escolas públicas estaduais de ensino médio. Os bolsistas licenciandos, no contexto da universidade, com a orientação do coordenador de área e com base nas aprendizagens dos conteúdos das aulas do curso, elaboram materiais pedagógicos e recursos audiovisuais para ser usados nas aulas de biologia ministradas nas escolas. No âmbito das escolas de educação básica, eles fazem o acompanhamento das aulas ministradas pelos professores da disciplina; orientam os alunos sobre os assuntos de biologia; participam na preparação de atividades pedagógicas da escola (exposições, mostras de ciências e campanhas educativas); elaboram, aplicam e corrigem avaliações e testes de conhecimento de biologia, visando as avaliações oficiais pelas quais os alunos passam, como o Exame Nacional de Ensino Médio (Enem).

A execução das atividades é feita em equipe, os bolsistas são alocados em grupos com a responsabilidade de estudar para, posteriormente, trabalhar com os alunos das escolas um conjunto de assuntos da biologia. Eles acompanham as aulas dos professores nas escolas e, no encerramento de determinado assunto, após o percurso de algumas aulas, fazem a revisão do conteúdo, com o uso de algum recurso audiovisual que elaboraram para esse fim. A prática de assistir às aulas dos professores de biologia nas escolas e conhecer o programa de conteúdos que é desenvolvido pelo professor contribui para que eles preparem recursos materiais e/ou aulas práticas para fazer a revisão dos assuntos com os alunos. Na visão dos licenciandos, o contato prévio - ou seja, ainda em momento de formação - com o cotidiano escolar permite uma aproximação significativa com a rotina da escola, bem como a observação e análise dos desafios encontrados na sala de aula e com a pluralidade presente naquele espaço. Além disso, contribui também para a troca de saberes e experiências entre eles, o que potencializa a formação individual e coletiva, assim como a reflexão sobre a escolha e permanência na profissão docente.

A orientação de estudos, que os bolsistas executam com os alunos, é realizada no próprio ambiente escolar e se efetiva na forma de atividades pedagógicas sob a supervisão do professor da disciplina na escola, bem como em práticas extraclasse (exposições, mostras de ciências e campanhas educativas). Nesse segundo caso, os bolsistas atuam na capacitação dos alunos, preparando com eles objetos que serão expostos à comunidade, assim como as formas didáticas de apresentação. As orientações aos licenciandos bolsistas são feitas periodicamente pelo coordenador de área no ambiente universitário. Elas podem ocorrer com um determinado grupo ou com o coletivo, envolvendo também os professores das escolas. Em tais momentos são 
discutidas relações de convivência social e trabalho em equipe, assim como aspectos concernentes às atividades realizadas nas escolas, como o planejamento de ações pedagógicas.

As práticas descritas acima, realizadas no contexto do Pibid, possuem os princípios do ideário sobre formação docente propalados por teóricos como Tardif (2004), Schön (2000), Zeichner (2010), Perrenoud (2002), entre outros. Elas concretizam a relação entre a teoria e a prática, são desenvolvidas no contexto real do processo de ensino e de aprendizagem, suscitam a reflexão sobre a ação, incentivam o trabalho em equipe e possibilitam a interação entre $a$ instituição formadora (universidade) e o local de futura atuação profissional (escola de educação básica). Tais aspectos são explicitados nos registros apresentados pelos participantes do Pibid, que a Capes coletou por meio de questionário (GATTI et al., 2014), e corroboram o que é apresentado de maneira implícita nos trabalhos divulgados em congressos e eventos nacionais de educação (Endipe, Anped, Anpae, Enalic).

É evidente, portanto, para nós que o Pibid se configura como uma importante ação pública governamental para a melhoria na formação inicial do professor. Não obstante, há aspectos limitadores do programa que necessitam ser ressaltados, visando o seu aperfeiçoamento e entendimento dos participantes. Em primeiro lugar, é preciso ter clareza de que ele está voltado especificamente para a formação inicial, e tem o potencial de estimular o ingresso dos jovens nos cursos de licenciatura, uma vez que concede uma bolsa de ajuda financeira e se mostra como atividade de inserção na prática escolar. Mas o programa, por si, não atinge problemas radicais da profissão, como valorização do magistério, conforme preconizado pela Capes no item II do art. 4 da Portaria 96/2013 (BRASIL, 2013); também não atinge as condições de trabalho do professor, que requer outros aspectos. Portanto, objetivamente, o Pibid não incentiva a permanência na profissão. Vários estudos (OCDE, 2006; VEZUB, 2005, 2007; DAVIS; NUNES; ALMEIDA, 2011; GATTI; SÁ BARRETO; ANDRÉ, 2011), em âmbito nacional e internacional, apontam que a valorização do magistério e da profissão docente envolve a formação inicial, mas não se limita a ela. Assim, o Pibid deve se constituir como uma ação no conjunto de uma política ampla de valorização do magistério que requer, entre outros fatores, necessariamente, formação inicial, formação continuada, forma de contratação, remuneração digna da profissão, condições de trabalho nas escolas e reforma curricular, pois, do contrário, podemos estar formando bons professores que posteriormente não permanecerão na carreira do magistério, ou, pelo menos, não ficarão na escola pública. 
Em segundo lugar, ressaltamos o limite de abrangência do programa. Considerando dados da Capes, publicados no trabalho de Gatti et al. (2014), atualmente o Pibid concede cerca de 90.000 bolsas, envolvendo alunos de licenciaturas, professores supervisores de escolas públicas, coordenadores de área e coordenadores institucionais. O programa atualmente atende a aproximadamente 5 mil escolas de educação básica e 284 instituições de ensino superior públicas e comunitárias. São números expressivos e revelam o aumento do Pibid desde sua criação, no ano de 2007, quando oferecia somente 3 mil bolsas, no âmbito das instituições de ensino superior federais, nas licenciaturas de matemática, biologia, física e química.

Não obstante os dados apresentados acima, a abrangência do Pibid ainda é baixa se considerarmos a quantidade de instituições de ensino superior (IES) e licenciandos no país. Segundo dados do censo da educação superior do ano de 2012, havia 2.416 IES, das quais 2.112 de gestão privada. 0 número de alunos nos cursos era de 7.037.688, com 73\% em IES não públicas (BRASIL, 2014). As matrículas nos cursos de licenciatura naquele ano somavam mais de 1.360 .000 , a grande maioria em instituições de gestão privada, pois elas ofertavam 66\% dos cursos de graduação do país. No ano de 2012 concluíram o curso de licenciatura mais de 223.000 alunos. Aproximadamente $68 \%$ dessa quantidade de egressos eram oriunda de IES privadas, que, majoritariamente, não fazem parte do Pibid. Além desses dados, é preciso considerar também a educação a distância. Segundo o censo de 2012, naquele ano eram 1.148 cursos, com 1.113.850 alunos matriculados, a maioria, como registrado no relatório, em licenciatura (BRASIL, 2014, p. 85), e que não participam do Pibid.

Em relação às instituições de ensino superior (IES) que participam do Pibid, percebemos a carência de um efetivo compromisso delas com o programa. Entendemos que as IES devem oferecer mais que a contrapartida mínima estabelecida pela Capes, como sala para ações administrativas, funcionário para suporte administrativo do programa, equipamentos para desempenho de rotinas administrativas, material de consumo e ramal telefônico (BRASIL, 2013), ou fazer ofertas voluntárias, como sugere o órgão.

A IES poderá oferecer outras contrapartidas complementares que julgar pertinentes, tais como estagiários, redução de carga horária dos coordenadores, incremento de recursos para compra de material permanente e custeio, bolsas adicionais para os estudantes de licenciaturas não contemplados com bolsa do Pibid, transporte para atividades ligadas a trabalhos de campo, entre outros (BRASIL, 2013, p. 7). 
Acreditamos que a IES deve assumir, de fato, um compromisso e corresponsabilidade com o programa, como uma política voltada para a formação inicial de professores. Assim, além da contrapartida citada, acrescentamos a necessidade de elas se comprometerem com o suporte e apoio institucional para divulgação do programa, apoio logístico para a realização das atividades nas escolas, auxílio na produção e na participação de eventos internos e externos do programa e a promoção e estímulo a discussões e debates sobre os currículos dos cursos de licenciatura oferecidos pela instituição com base nas ações do Pibid, uma vez que, conforme relatam os bolsistas, o Pibid expõe as fragilidades da formação oferecida nos cursos (GATTI et al., 2014), como, por exemplo, currículos sem atualização, alta carga horária teórica, excesso de disciplinas, pouca prática, metodologias e formas de avaliação com pouca contribuição para a formação do professor, currículos sem flexibilidade e autonomia acadêmica do aluno.

\section{CONCLUSÃo}

Nossa vivência como bolsistas do Pibid, tanto no contexto escolar como no universitário, além do compartilhamento de experiências, por meio de eventos, com aqueles que fazem o programa acontecer em diferentes realidades, assim como o exame de documentos oficiais e textos que orientam e discutem suas ações, nos possibilitam entender e considerar sua importância para a formação inicial do professor. “[...] Sem dúvida [...], esse é um programa de grande efetividade no que se refere à formação inicial de professores" (GATTI et al., 2014, p. 103). Tal importância se torna explícita, como mostram os autores, nos registros dos vários professores e alunos bolsistas do Pibid.

Objetivamente o programa atua com o foco na formação inicial de professores, porém os efeitos de suas ações atingem, ainda que de maneira tímida, a formação continuada e a melhoria da qualidade do ensino em algumas escolas de educação básica, além de provocar reflexões sobre os cursos de licenciatura, na medida em que expõem as fragilidades e o descompasso da formação acadêmica com a realidade das escolas, conforme revelam os dados coletados pela Capes e analisados por Gatti et al. (2014). Não obstante, o programa possui, em nosso entendimento, limitações que precisam ser evidenciadas. Em primeiro lugar, compreendemos que não se trata de uma política de estímulo à carreira docente, mas uma ação visando à melhoria da 
formação inicial do professor. Essa é uma característica que não o desmerece, ao contrário, revela seu escopo no bojo de uma intenção maior de valorização da profissão, que ainda precisa ser implantada. Em segundo lugar, o programa tem abrangência restrita, pois está concentrado, majoritariamente, nas IES públicas e atinge menos de $10 \%$ dos alunos dos cursos de licenciatura do país. Esse fato exige, portanto, a necessidade de maior aporte de recurso financeiro do poder público para esse fim. Outro aspecto importante para otimizar a ação do Pibid na melhoria da formação inicial de professores é o estabelecimento de uma proximidade da Capes com os gestores acadêmicos das IES, com o intuito de constituir uma relação de compromisso e corresponsabilidade efetiva dos gestores com o desenvolvimento do programa, sobretudo no que diz respeito a promover e estimular debates e ações que visam à reflexão sobre os currículos e metodologias de ensino dos cursos de licenciatura. 


\title{
Inputs and limits of Pibid as a government policy for teacher education
}

\begin{abstract}
The Programa Institucional de Bolsa de Iniciação à Docência (Pibid) [Institutional Program of Initiation to Teaching Scholarship] is already consolidated as a government policy for teacher education. The Coordenação de Aperfeiçoamento de Pessoal de Nível Superior (Capes) [Coordination of Graduate Pesonnel Improvement], an institution linked to the Ministério da Educação (MEC) [Department of Education] and participants in the program at graduate institutions consider it important for teachers' initial and continuing education, as well as for improving teaching quality at elementary public schools and valuing the teaching profession. We agree with its importance for initial education and present in this text our experience with this subject. However, more than that we suscitate a debate about the program's limitations concerning the range of the beneficiaries and other aspects pointed out by those receiving a scholarship and by Capes. We conclude by saying it is necessary to enlarge the program and have IESs more commited to it and to teacher education.
\end{abstract}

Keywords: Government public policies. Pibid. Teacher education. 


\section{REFERÊNCIAS}

ANDRÉ, Marli. Políticas e programas de apoio aos professores iniciantes no Brasil. Cadernos de Pesquisa, São Paulo, v. 42, n. 145 p. 112-129, jan./abr. 2012. Disponível em: $\quad$ http://publicacoes.fcc.org.br/ojs/index.hp?journal=cp\&page=article\&op= view\&path\%5B\%5D=50\&path\%5B\%5D=65> Acesso em: 5 jul. 2014.

BALL, D. L.; COHEN, D. K. Developing practice, developing practitioners: Toward a practice-based theory of professional education. In: SYKES, G.; DARLINGHAMMOND, L. Teaching as the learning profession: handbook of policy and practice: 3-32. San Francisco: Jossey Bas., 1999. Disponível em: 〈http://wwwpersonal.umich.edu/ dball/chapters/BallCohenDevelopingPractice.pdf $\rangle$. Acesso em: 12 fev. 2014.

; FORZANI, F. M. The work of teaching and the challenge for teacher education. Jornal of Teacher Education, v. 60, n. 5, p. 497-511, 2009. Disponivel em: «http:// www.ctc.ca.gov/educator-prep/TAP/JTE_The_Work_of_Teaching.pdf $\rangle$. Acesso em: 12 fev. 2014.

BRASIL. Coordenadoria de Coordenação de Aperfeiçoamento de Pessoal de Nível Superior. Portaria no 96, de 18 de julho de 2013. Regulamento do Programa Institucional de Bolsa de Iniciação à Docência (Pibid). Disponível em «www.capes. gov.bry. Acesso em: 20 ago. 2013.

. Presidência da República. Decreto no 7.219, de 24 de junho de 2010. Decreto que Dispõe sobre o Programa Institucional de Bolsa de Iniciação à Docência Pibid e dá outras providências. Diário Oficial da República Federativa do Brasil, Brasília, 25 jun. 2010. Seção 1, p. 4.

. Ministério da Educação. Portaria Normativa no 38, de 18 de julho de 2013. Aprova o regulamento do Programa de Bolsa Institucional de Iniciação à Docência - Pibid. Diário Oficial da República Federativa do Brasil, Brasília, 23 jul. 2013. Seção 1, p. 11.

- Ministério da Educação. Resumo Técnico Censo da Educação Superior 2012. Instituto Nacional de Estudos e Pesquisas Educacionais Anísio Teixeira (Inep): Brasília, 2014.

DAVIS, C. L. F.; NUNES, M. M. R.; ALMEIDA, P.C.A. Formação continuada de professores: uma análise das modalidades e das práticas em estados e municípios brasileiros. Relatório final. São Paulo: Fundação Victor Civita, Fundação Carlos Chagas, 2011.

GATTI, B. A.; SÁ BARRETO, E. S.; ANDRÉ, M. E. D. F. Políticas docentes no Brasil: um estado da arte. Brasília: Unesco, 2011. 
et al. Um estudo avaliativo do Programa Institucional de Bolsa de Iniciação à Docência (Pibid). São Paulo: Fundação Carlos Chagas, 2014. Disponível em: 〈http://capes.gov.br/images/stories/download/bolsas/24112014-pibid-arquivo Anexado.pdf〉. Acesso em: 5 jan. 2015.

GUIMARÃES, J. A. Apresentação. In: GATTI, B. A. et al. Um estudo avaliativo do Programa Institucional de Bolsa de Iniciação à Docência (Pibid). São Paulo: Fundação Carlos Chagas, 2014. Disponível em: 〈http://capes.gov.br/images/stories/ download/bolsas/24112014-pibid-arquivoAnexado.pdf〉. Acesso em: 5 jan. 2015.

OCDE. Professores são importantes: atraindo, desenvolvendo e retendo professores eficazes. Relatório de pesquisa. São Paulo: Moderna, 2006.

PERRENOUD, P. A prática reflexiva no ofício de professor: profissionalização e razão pedagógicas. Porto Alegre: Artmed, 2002.

POGGI, M. Prólogo. In: FANFANI, E. T. El oficio docente: vocación, trabajo y profesión en el siglo XXI. Buenos Aires: Editores Argentina: 2006. 9-11 p. Disponível em: 〈http://toolkit.ineesite.org/toolkit/INEEcms/uploads/1048/El_oficio_de_ docente.pdf $\rangle$. Acesso em: 22 maio 2014.

SCHÖN, D. A. Educando o profissional reflexivo: um novo design para o ensino e a aprendizagem. Porto Alegre: Artmed, 2000.

TARDIF, Maurice. Saberes docentes e formação profissional. Petrópolis: Vozes, 2004.

VASQUEZ, A. S. Filosofia da práxis. 3. ed. Rio de Janeiro: Paz e Terra, 1977.

VEZUB, L. F. Tendências internacionales de desarrollo profesional docente. La experiência de México, Colômbia, Estados Unidos y España, 2005. Disponível em: 〈http://www.redmaestrosdemaestros.cl/usuarios/nseve/doc /200911252152150. Tendencias_internacionales_de_desarrollo_profesional_docente_LFVezub.pdf . Acesso em: 20 mar. 2013.

La formación y el desarrollo profesional docente frente a los nuevos desafíos de la escolaridade. Revista de Currículum y Formación de Profesorado, v. 11, n. 1, p. 1-23, 2007. Disponível em: 〈http://www.ugr.es/ recfpro/rev111ART2.pdf〉. Acesso em: 20 mar. 2013.

ZEICHNER, K. M. Educação: repensando as conexões entre a formação na universidade e as experiências de campo na formação de professores em faculdades e universidades. Educação Santa Maria, v. 35, n. 3, p. 479-504, 2010.

RECEBIDO: Abril de 2015.

APROVADO: Maio de 2015. 